\title{
LA REVOLUCIÓN NICARAGÜENSE A TRAVÉS DE TESTIMONIOS ORALES
}

\author{
Ignacio Dueñas García de Polavieja \\ UnIVERSIDAD DE CÁDIZ
}

\section{RESUMEN}

El presente artículo trata acerca de la revolución sandinista de Nicaragua (19791990). De este modo, veremos cómo a partir de la toma del poder, que abrió una etapa de sueños, fraternidad y utopía, se llevó a cabo un intento serio de construir una sociedad más humana, democrática e igualitaria, así como respetuosa de los derechos humanos. El acoso sistemático de los grupos oligárquicos y del gobierno de EEUU, dio al traste con todo el proceso una década después de su triunfo. Además, a partir de la Asamblea Constituyente de 1986 que dio pie a la Constitución, se procedió a la institucionalización y corrupción de la revolución.

PALABRAS CLAVE: Nicaragua, revolución, FSLN, reforma agraria, alfabetización.

\section{ABSTRACT}

The present article there treats of the evolution of the revolution Sandinista of Nicaragua (1979-1990). This way, from the capture of the power, which opened the first stage of dreams, brotherhood and utopia, there was carried out a serious attempt of constructing a more human, democratic and egalitarian society as well as respectful of the human rights. The systematic harassment of the oligarchical groups and of the government of the USA, met to the fret the whole process a decade after his victory. In 
addition, from the Constituent Assembly of 1986 that gave course for the Constitution one proceeded to the institutionalization and corruption of the revolution.

KEY WORDS: Nicaragua, revolution, FSLN, agrarian reform, literacy.

\section{INTRODUCCIÓN}

El presente artículo forma parte de un trabajo de investigación para el que viajé durante casi tres meses por buena parte de Nicaragua. La finalidad de esta iniciativa consistió en recabar testimonios orales a partir de los cuales poder reconstruir la Historia Actual del país centroamericano, así como sus principales acontecimientos.

Uno de éstos consistió en la toma del poder por parte de la guerrilla del FSLN el 19 de julio de 1979, día en que liquidó manu militari la dictadura de la familia Somoza, dueña del país durante unas cuatro décadas. Ese mismo día comenzó la reconstrucción de Nicaragua mediante un nuevo orden dotado de influencias socialistas, cristianas, democráticas y humanistas.

\section{LA EUFORIA E ILUSIÓN DE LOS PRIMEROS MOMENTOS}

Según recuerda el poeta Ernesto Cardenal, el día del triunfo fue una gran fiesta en la Plaza de la Revolución. Allí, unas 200.000 personas con banderas rojinegras, muchas de ellas apretadas en las cornisas y en las torres de la catedral, celebraron entusiastamente la victoria mediante una gran histeria colectiva bajo el sol brutal del mediodía de Managua ${ }^{1}$. Otros testimonios dan fe de semejante clamor popular:

"Bueno, me acuerdo que fueron miles y miles de gente viniendo de Masaya, de León, del norte, de todas partes...concentrándose en la plaza, aquella bla, aquella euforia enorme de gente que había, y la sensación enorme de sentirnos liberados para siempre de la dictadura somocista, y de vivir una nueva etapa [...] de tremenda emoción, tremenda euforia"².

Asimismo, el jesuita Fernando Cardenal tampoco fue el epítome de la calma en aquellos momentos de alegría incontrolada, llegando a adoptar una actitud algo temeraria, según él mismo reconoce:

"Cuando yo oí por radio en la madrugada, tempranito, que en la madrugada se había ido Somoza, con sus principales oficiales, yo salí en pijama de mi casa de seguridad con una metralleta [...], tiraba una ráfaga: ra-ra-ra-ra-ra, “ ¡viva la revolución sandinista!’[...]. Una cosa imprudente porque [...] en esa calle podía haber oficiales de Somoza, que me pudieran oír”’3.

\footnotetext{
1 CARDENAL, Ernesto: La revolución perdida. Memorias 3, Madrid, Editorial Trotta, 2003, pp. 223-24.

2 Entrevista efectuada por el autor a Rafael Valdés Rodríguez, Managua, 1 y 2 de agosto de 2008.

3 Entrevista realizada por el autor a Fernando Cardenal, S.J. en Managua, 28 de julio de 2008.
} 
Quedaba por delante la reconstrucción de un país completamente destrozado. Según datos de la CEPAL, la lucha costó unos 35.000 muertos, así como 480 millones de dólares, además de otros 1.500 millones a modo de fuga de capitales ${ }^{4}$. Sin embargo, el entusiasmo sin límites del pueblo hizo que éste se lanzara con mucho entusiasmo a la reconstrucción de Nicaragua:

"Estábamos dispuestos...además, ¡dispuestos todos! ¡A darlo todo! ¡Si la gente había dado su vida!: ; en las calles, en las insurrecciones populares, en la... en la montaña, en las ciudades, en las barricadas, en...!"’.

Así, gracias a la capacidad de entrega de los nicaragüenses y al FSLN, se abrió una etapa de participación fascinante ${ }^{6}$. Las principales campañas fueron las de recogida de algodón y de café con vistas a levantar la producción. Una religiosa, informante anónima, lo recuerda con las siguientes palabras:

"Nosotras nos organizamos en el barrio [...]: éramos cuatro hermanas y estábamos trabajando con los dominicos y...y en cada sector del barrio pues había comisiones, había... se empezaron a formar los CDI, se empezaron a formar las... las...los grupos comunitarios pues [...]: bueno, ya más adelantito se organizó la sección de ir a los cortes: cortes de café, los cortes de algodón, de caña"’

Así, según Mercedes Ortega, el horario de la jornada del algodón era de 7 a 12 de la mañana y de 2 a 4 de la tarde ${ }^{8}$. Por otra parte, se trataba de una actividad incómoda, según la propia informante, aunque "esas jornadas fueron muy contentas [...]: la gente realmente [...] se metió con mucho entusiasmo: la gente iba muy...se cantaba" ${ }^{\text {. De }}$ este modo, entre inconvenientes y espíritu solidario, se daban a la labor:

"El algodón es pesado, (pues) es un solazo: un solazo, y las ramas se secan y tienen como espinas y te hieren, y te rayan: hay que andar con camisas manga larga, con sombreros grandes, llevar tus botellas de agua, llevar tus botas, porque... es bastante pesadito. Más sin embargo fue a lo que más fui: al algodón, porque iba...me monté en una brigada de fines de semana" ${ }^{10}$.

El jesuita mexicano Arnaldo Zenteno, llegado al país por esas mismas fechas, rememora toda esa euforia de ilusión y reconstrucción ${ }^{11}$ :

4 VILAS, Carlos M.: La revolución sandinista, Buenos Aires, Editorial Legasa, 1984, p. 211.

5 Entrevista realizada por el autor a Julio Valle-Castillo en Managua el 13 de septiembre de 2008.

6 Ibídem.

7 Testimonio de una informante anónima. Centros de Desarrollo Infantil (CDI) son preescolares, donde se imparte atención integral previa a la primaria (Nota del autor).

8 Entrevista realizada por el autor a Mercedes Ortega en Managua, el 9 de septiembre de 2008.

9 Ibídem.

10 Ibídem.

11 Cerezo Barredo y Teófilo Cabestrero, testigos de aquellos días, los describen en clave poética mediante los siguientes términos: "Se levanta la nueva ciudad, una ciudad comunitaria. La nueva Nicaragua nicaragüizada. Simétrica sinfonía de fusiles, adoquines, ladrillos, muros (hospitales, escuelas, viviendas), poemas, flores, cartillas, libros, tractores, brazos, abrazos, parques, danzas, sueños...Realidades". (CEREZO BARREDO, Maximino y CABESTRERO, Teófilo: Lo que hemos visto y oído. Apuntes en la revolución de Nicaragua, Bilbao, Desclee de Brouwer, 1983, p. 64). 
"Esa semana que estuve aquí me tocó empaparme más [...] de la luna de miel: era el tiempo de la luna de miel, después del triunfo revolucionario: toda la gente contenta, alegre, soñando, ¿no? Estaban en campaña de vacunación [...], estaban en la alfabetización [...], había cortes de café con muchos voluntarios... era como un sueño"12.

Otra actividad fundamental era la vigilancia revolucionaria ${ }^{13}$, a cuyo frente se encontraban los CDS, o Comités de Defensa Sandinista, pues según una informante anónima, "en el barrio, cada manzana había... había como comité [...], donde se veían los problemas, donde se veían las cosas que había que ir solucionando [...]: a veces la limpieza del barrio [...]"14. Jamil Ríos recuerda cómo de niño, su madre, líder del barrio, realizaba su turno en las jornadas nocturnas de vigilancia:

"Y entonces, hacían vigilancia revolucionaria, que era, en las noches, de 11 a 5 de la mañana hacían vigilancia los vecinos, algunos encargados. Entonces me acuerdo que los días que le tocaba a mi mamá, le tocaba con un grupito del barrio, muy buena gente [...]. Y entonces...y me acuerdo que yo me quedaba con mi mamá haciendo la vigilancia. A mí me encantaba [...]. Si, por ejemplo, pasaba alguien: “Compañero, ¿para dónde va?”, “ipara tal lado!”. Decía: “¡Cómo no: le acompañamos!” [...], y lo acompañaban hasta el siguiente sector para enlazarlo con el otro...vigilancia [...]. Yo me acuerdo de las noches, del café [...]. Había una especie de...espíritu de solidaridad. Todos éramos compañeros"15.

\section{REVOLUCIÓN Y REDISTRIBUCIÓN DE LA RIQUEZA}

Era pues el momento de que el grupo guerrillero, ya triunfante, aplicase su programa de gobierno ${ }^{16}$. Desde el punto de vista político, el primer gabinete revolucionario se caracterizó por el pluralismo en todas las instancias de poder ${ }^{17}$, entre ellas: el mismo ejecutivo, el Consejo de Estado, el sistema judicial, los medios de comunicación, la patronal y los sindicatos, las iglesias, los partidos, la producción y el comercio interior ${ }^{18}$.

\footnotetext{
12 Entrevista realizada por el autor a Arnaldo Zenteno Vargas, S.J., en Managua el 22 de julio de 2008.

$13 \mathrm{La}$ vigilancia revolucionaria era un sistema de defensa consistente en 90.000 voluntarios que cada noche vigilaba calles, plazas, talleres, fábrica, vidas, etc. Organizados por turnos y divididos por cuadras, su objetivo era abortar la delincuencia común y las actividades contrarrevolucionarias. (CEREZO BARREDO, Maximino y CABESTRERO, Teófilo: op. cit., 1983, p. 139).

14 Testimonio de una informante anónima.

15 Entrevista realizada por el autor a Yamil Alberto Acuña Ríos en Managua el 30 de julio de 2008.

$16 \mathrm{El}$ proyecto del sandinismo en el poder se resume en las siguientes apuestas: existencia de un gobierno revolucionario pero con la participación plena de todo el pueblo, la nacionalización de los bienes de Somoza y las de propiedad extranjera, la nacionalización del comercio exterior, la reforma agraria, la extensión de la educación pública, la integración de la Costa Atlántica y la emancipación de la mujer, entre otras. (MARTÍ I PUIG, Salvador y FIGUEROA IBARRA, Carlos, La izquierda revolucionaria en Centroamérica. De la lucha armada a la participación electoral, Madrid, Los Libros de la Catarata, 2006, p. 56).

17 Este pluralismo contó con dos obvias excepciones: el de los grupos somocistas, o el de los que entregaran espacios de soberanía nacional a potencias extranjeras. (CORAGGIO, José Luis, Nicaragua: Revolución y democracia, Buenos Aires, Bibliotecas Universitarias, Centro Editor de América Latina, 1986, pp. 28-29). 18 Este pluralismo gubernamental se produjo a nivel de la presidencia colegiada, de la composición de los ministerios y del funcionariado. (Ibídem, p. 29).
} 
Las principales medidas encaminadas a una efectiva redistribución de la riqueza ${ }^{19}$, dieron paso al surgimiento de una economía mixta en virtud de la cual, el sector privado, que fue respetado ${ }^{20}$, invertía y producía, mientras que el gobierno revolucionario garantizaba el crédito, la tecnología y las materias primas, y se encargaba de tasar los $\operatorname{precios}^{21}$.

Sin embargo, las disensiones dentro del seno de la coalición gubernamental no tardaron en aparecer: en abril de 1980, el FSLN introdujo unilateralmente a las Organizaciones de Masas en el Consejo de Estado, que otorgaron al sandinismo una mayoría aplastante en las votaciones. Como protesta ante esta medida, Alfonso Robelo y Violeta Chamorro, representantes de la burguesía en el gobierno, dimitieron ${ }^{22}$ para pasar a una oposición que, progresivamente, se transformó en subversión armada ${ }^{23}$.

Aunque pueda parecer desmesurada la actitud de la burguesía al disentir así del proceso revolucionario, lo cierto es que como bloque de poder veía que este nuevo sistema resultaba catastrófico de cara a sus intereses. Según Orlando Núñez Soto, la oligarquía había perdido el $40 \%$ de su riqueza, así como el control de la política económica interna y externa ${ }^{24}$.

Con respecto a las medidas sociales de la revolución, una de las más importantes fue la reforma agraria, llevándose a cabo durante los primeros meses del proceso mediante una repartición de tierras ${ }^{25}$ entre jornaleros y pequeños y medianos propietarios ${ }^{26}$. Esta iniciativa se tradujo en que el $30 \%$ de las tierras cultivables pasara a pertenecer a 2.000 cooperativas, quedando otro $30 \%$ como propiedad estatal, de modo que el $40 \%$ restante permaneció en manos privadas ${ }^{27}$. Un beneficiario da fe del siguiente modo:

"Entonces, el Estado vino y dijo: "bueno: las tierras, ¿verdad?, pasarán a los campesinos" [...]. Así fue: estas tierras fueron entregadas por reforma agraria, así es como vine a Santa $\operatorname{Rosa}^{28}$. Si no nos organizamos tan bien y no hubiera

19 Entre estas medidas se contaron la expropiación de los bienes de Somoza y sus testaferros, la nacionalización de la banca, la expropiación de casas y terrenos baldíos, la reforma agraria y la nacionalización del comercio exterior. (SANABRIA, Octavio y Elvira, Nicaragua: diagnóstico de una traición. El Frente Sandinista de Liberación Nacional en el poder, Barcelona, Plaza Janés Editores SL, 1986, p. 221).

20 CORAGGIO, José Luis: op. cit., 1986, p. 28.

21 MARTÍ I PUIG, Salvador: Tiranías, rebeliones y democracia. Itinerarios políticos comparados en Centroamérica, Barcelona, Edicions Bellaterra, 2004, p. 183.

22 MOLERO, María: Nicaragua sandinista: del sueño a la realidad (1979-1988), Managua, CRIES/Fundación Bofill/IEPALA Editorial, 1988, p. 56.

23 En un principio, las acciones de la burguesía para atacar a la revolución fueron moderadas: boicot a la campaña del café, o tiroteos a manifestantes por parte de vigilantes armados desde la sede del diario $L a$ Prensa. Sin embargo, pronto evolucionó al terrorismo de la denominada contra, que, como veremos más adelante, con ayuda norteamericana comenzó en 1982 una campaña violenta de sabotajes, secuestros y acciones armadas. (NÚÑEZ SOTO, Orlando: Transición y lucha de clases en Nicaragua. 1979-1986, México DF, Siglo Veintiuno Editores, 1987, p. 127).

24 Ibídem, p. 119.

25 Para llevar a cabo esta reforma no fue necesaria la confiscación masiva de tierras: bastó con nacionalizar las pertenecientes a Somoza y sus testaferros, que ocupaban la tercera parte de las del total del país. (BROOK, Chris: "Ahora sí ya sabemos cuál es la diferencia", Revista Cultural Nicaráuac No 12, Managua, Nicaragua, Revista del Ministerio de Cultura, Abril, 1986, p. 42).

26 En función de la ley que la impulsó, se fomentó el cooperativismo entre jornaleros y pequeños y medianos propietarios, mediante la asesoría, el crédito y la entrega de maquinaria. Por otra parte, se estableció que toda finca deficientemente explotada, podía ser expropiada y entregada al pueblo para ser puesta a producir mediante el régimen de cooperativa. (GARCÍA, Diamantino: Como un diamante. Escritos de Diamantino García, Madrid, Editorial Nueva Utopía, 1996, p. 537).

27 Ibídem, p. 551.

28 Las tierras donde se levantó la cooperativa de Santa Rosa pertenecían al terrateniente somocista Mauro 
habido reforma agraria no estuviéramos aquí tampoco [...]: al llegar el gobierno de reconstrucción nacional, comienza a ver los bancos, y las propiedades, cómo están, ¿verdad?"29.

Además, mediante la universalización de la canasta básica se erradicaron la desnutrición y el hambre ${ }^{30}$. La informante, Amparo Rubio, así lo afirma de un modo tajante:

"A pesar de que estábamos en guerra, con el bloqueo que nos habían mon$\operatorname{tado}^{31}[\ldots]$, hermano, aquí comíamos, que me diga a mí quién no, quién aguantó hambre. Nadie. Había comida: arroz, frijoles, aceite. Y había economía de patio: a la gente se le enseñó a tener gallinas, a tener cerdos...lo básico"32.

En definitiva, la nómina de los logros fue ingente: el gasto social pasó del 4 al 8\% del PIB entre los años 1978 y 1982, principalmente en salud y educación. Se dobló el número de escuelas de 500 mil a un millón, y se garantizó la gratuidad de la enseñanza. Los centros de salud pasaron de 180 a 480, disminuyendo la mortalidad infantil del 120 al 58 por mil, y erradicándose numerosas enfermedades. Por último, se creó una red de tiendas alimenticias consistente en 100 grandes establecimientos populares y en 6 mil puestos de distribución cuyos precios estaban controlados para hacerlos accesibles a toda la población ${ }^{33}$.

El veterano sandinista René Vega, analiza con las siguientes palabras el salto cualitativo gozado por los nicaragüenses a la sombra del nuevo proceso:

"Aunque fue un poco corto tiempo [...], significó mucho para la gente, para el pueblo [...]: los aciertos fueron muchísimos [...] por materia de salud, educación, etc. [...]. Cuando uno participa y mira que el pueblo está feliz, con que la educación es gratuita, con que la salud es gratuita, que el estudiante se mueve gratuitamente en un bus [...], uno siente una satisfacción...o que el campesino tiene sus títulos" 34 .

Vilche, cuyo latifundio se construyó mediante el expolio de tierras a sus anteriores propietarios. Huido a Miami en 1978, tras el triunfo de la revolución, el INRA y UNAG, organismos sandinistas, le conceden a la cooperativa la propiedad de las tierras en 1983. El comandante Jaime Wheelock Román les extendió el título de propiedad (TRAYNER, Mari Pau: Una esperanza para la Iglesia. Comunidades Eclesiales de Base de Nicaragua, Zaragoza, Comunidades Eclesiales de Base de Nicaragua/Comité Cristiano de Solidaridad Óscar Romero de Aragón, 2000, pp. 235-36).

29 Entrevista realizada por el autor a Emilio Blandón Sánchez en Santa Rosa (Ocotal), el 11 de julio de 2008.

30 KLOMBERG, Theo: Algo más que un beso. En camino con el pueblo de Sandino, Managua, 2004, p. 93). 31 La agresión militar proestadounidense de la contra distorsionó la totalidad de la vida del país, y sobre todo de la economía, ya que hasta el $50 \%$ de los recursos presupuestarios y el $20 \%$ de la población activa fue absorbida por el esfuerzo defensivo. (MARTí I PUIG, Salvador: op. cit., 2004, p. 168). En un principio se cortaron los préstamos y donaciones de organismos controlados por la Casa Blanca como el BID, el BM o la AID. Posteriormente se cortaron las cuotas de carne, bananos, azúcar y mariscos. Y en mayo de 1985 se impuso a Nicaragua un embargo comercial que no sólo afectó a productos, sino al suministro de insumos y maquinaria para la producción. (NÚÑEZ SOTO, Orlando: op. cit., 1987, p. 181).

32 Entrevista realizada por el autor a Amparo Rubio, Ocotal, 11 de agosto de 2008.

33 NÚÑEZ SOTO, Orlando: op. cit., pp. 104-05.

34 Entrevista realizada por el autor a René Santiago Vega Reyes, Managua, 6 de septiembre de 2008. 


\section{LA CRUZADA NACIONAL DE ALFABETIZACIÓN}

Sin embargo, la más intensa de las campañas de la revolución fue la cruzada ${ }^{35}$ de alfabetización. Tal y como apunta el ignaciano Arnaldo Zenteno, ésta consistió en hacer descender el analfabetismo del 60 al 12\% aproximadamente, mediante la participación voluntaria de estudiantes de secundaria, bachillerato y universidad que durante 5 meses fueron a la montaña a enseñar a leer y a escribir a los campesinos ${ }^{36}$.

La iniciativa comenzó con el encargo del gobierno revolucionario al jesuita Fernando Cardenal, quien aceptó entusiasmado sin importarle que para tan vasta tarea no se le diese presupuesto alguno, dada la ruina de las cuentas del Estado tras la insurrección ${ }^{37}$.

Partiendo de cero, debió procurarse voluntarios y fondos ${ }^{38}$ para comenzar a elaborar un censo fiable acerca del número de analfabetos y su ubicación geográfica concreta. De nuevo el testimonio de Fernando Cardenal:

"El censo lo hicimos nosotros. La UNESCO nos asesoró. Lo hicimos sin gastar. ¿Cómo? Miles de jóvenes en las montañas. Se les dio la instrucción [...]. Con mapas, dónde están las casitas de los analfabetos [...]. Eso lo hicimos, el censo, con centenares, miles de jóvenes voluntarios [...]. Y me dijo la de la UNESCO: "Este censo tiene una autoridad moral muy grande" 39 .

Tras solventar la gran dificultad de conseguir equipamiento e instrumental para 60.000 movilizados (botas, uniformes, mochilas, hamacas, cuadernos...) ${ }^{40}$, la campaña finalmente comenzó. Así recuerda una veterana las clases que impartían:

"Llegábamos a las 6 de la tarde [...], eran dos horas de clase: era una hora teórica y otra hora práctica [...]. Primero había mucha intención de que se les hablaran a ellos de cosas cotidianas, pues, que ellos no sintieran que ya eran mayores [...], y luego pues este... sí: irles metiendo pues lo que era las palabras, las letras, que ellos contaran, que expresaran sus...sus experiencias, lo que conocían, lo que no conocían" $"$.

35 Se le puso el nombre de cruzada para subrayar su carácter de movimiento popular masivo dotada de una mística y un entusiasmo arrolladores. (CARDENAL, Fernando: Sacerdote en la revolución. Memorias. Tomo II, Managua, Anamá Ediciones, 2008, p.11).

36 Entrevista realizada por el autor a Arnaldo Zenteno Vargas, S.J., en Managua el 22 de julio de 2008.

37 CARDENAL, Fernando: op. cit., 2008, pp. 9 y 269.

38 Ibídem, pp. 15 y 18. La cuestión financiera se solventó buscando fondos cómo y de dónde se pudo. A modo de ejemplo, el pedagogo brasileño Paulo Freire fue invitado a Nicaragua como asesor de la Cruzada. La impresión que se llevó del ambiente, del ánimo y de la ilusión debió ser tal, que en un momento dado tomó el teléfono, llamó al Consejo Mundial de Iglesias y textualmente dijo: "Esta es una revolución bella, pura y limpia como una niña; hay que apoyarla, y hay que apoyar la Cruzada de Alfabetización”. Como consecuencia de esa llamada, Freire consiguió del organismo la donación de un millón de dólares, la mayor que se llegó a conseguir para tal fin.

39 Entrevista realizada por el autor a Fernando Cardenal, S.J. en Managua, el 28 de julio de 2008. Para llevar a cabo el censo, los organizadores demandaron ayuda a la UNESCO, respondiendo ésta que se necesitarían 3.000.000 de dólares y dos años. No disponiendo de ese dinero ni de ese tiempo, decidieron hacerlo sin este organismo internacional. Les costó 30.000 dólares y tardaron un mes. La UNESCO avaló el método y el resultado. El gobierno respondió que la clave del éxito radicó en llevar a cabo la campaña sin ayuda de la dicha institución, y recurriendo al voluntariado. (LACAYO, Francisco: "Insurrección cultural e insurrección evangélica”, VVAA: Nicaragua, trinchera teológica. Para una teología de la liberación desde Nicaragua, Managua, Centro Ecuménico Antonio Valdivieso, 1987, p. 333).

40 Entrevista realizada por el autor a Fernando Cardenal, S.J. en Managua, el 28 de julio de 2008.

41 Entrevista realizada por el autor a Mercedes Ortega en Managua, el 9 de septiembre de 2008. 
La jornada de los alfabetizadores fue, por otra parte, como sigue:

"Bueno, mire: en la mañana [...] yo iba a lavar mi ropa al río, me iba a bañar. Después comía, me iba a ayudar y hacía algún... a algún campesino que yo mirara que había necesidad de ayudarle, yo lo iba a ayudar a trabajar al campo [...], y yo me iba con el azadón, a ayudarle. $Y$ en la tarde, yo, una hora antes de irme para el...para donde iba a dar clases, yo tenía que planear la clase, hacía un diario de campo todos los días" ${ }^{42}$.

Además, se debe resaltar el heroísmo de los alfabetizadores, siendo adolescentes, de enseñanza secundaria buena parte de éstos, los más pequeños de tan sólo 13 años ${ }^{43}$. Ante tanta juventud, la contra comenzó a matar voluntarios, hasta 7 a lo largo de la campaña; sin embargo, nadie se rindió y todos siguieron trabajando ${ }^{44}$. Así recuerda Fernando Cardenal cómo fue recibido por una brigada de chavalas al ir a dar la cara a causa del asesinato de una de sus miembros por los terroristas:

"Entonces, en uno de los helicópteros me voy para allá a donde estaba la escuadra de la muchacha que habían asesinado, [...] llego con miedo de que los jóvenes, ante el asesinato, comiencen a bajarse de las montañas. [...]. Me reciben las veintinueve muchachas en posición de firmes, me bajo del helicóptero y me reciben con dos consignas: "Ni a balazos ni a patadas nos sacarán de la cruzada" [...]. Un impacto que tuve yo fortísimo" 45 .

Finalmente, tras 4 meses de riesgos y esfuerzos, la campaña llegó a su fin. El acto de clausura resultó inolvidable:

“La entrega de graduación? Hubo mucho...fue muy emotivo, fue muy emotivo. Hubo mucha gente que incluso lloró pues a la hora que entregaron sus diplomas: se sintieron muy agradecidos" ${ }^{\prime \prime 6}$.

El teólogo José Ignacio González-Faus, quien se encontraba presente, recuerda cómo en la ceremonia la muchacha que iba leyendo los nombres de los alfabetizados para que subieran a recibir un abrazo y un diploma, no pudo continuar con su labor: se tuvo que ir a un rincón a llorar por la emoción de lo que estaba viviendo. Otro compañero le sustituyó de modo improvisado ${ }^{47}$.

Este mismo teólogo sostiene que la proeza de la cruzada, premiada y alabada por la UNESCO, es comparable a las pirámides de Egipto y a la gran muralla china ${ }^{48}$. Lo cierto es que su responsable, tras el acto de clausura, pensó que "ya me podía morir tranquilo" 49 .

42 Entrevista efectuada por el autor a Francisco Apolinar Matutes en Palacagüina, el 17 de agosto de 2008. 43 Una de las enseñanzas aprendidas de Fernando Cardenal en la cruzada es la afirmación de Paul Claudel de que los jóvenes están hechos para el heroísmo. (CARDENAL, Fernando: op. cit., 2008, pp. 14-15, 48 y 59). 44 Entrevista realizada por el autor a Fernando Cardenal, S.J. en Managua, el 28 de julio de 2008.

46 Entrevista realizada por el autor a Mercedes Ortega en Managua, el 9 de septiembre de 2008.

47 CARDENAL, Ernesto: op. cit., 2004, pp. 294-95.

48 CARDENAL, Fernando: op. cit., 2008, pp. 100 y 102.

49 Entrevista realizada por el autor a Fernando Cardenal, S.J. en Managua, el 28 de julio de 2008. 


\section{REVOLUCIÓN Y DERECHOS HUMANOS}

Otro considerable logro de la revolución fue el respeto a los derechos humanos de los vencidos y opositores. Tras la victoria, no sólo no hubo ejecuciones, algo verdaderamente insólito hasta la fecha a lo largo de la historia mundial ${ }^{50}$, sino que no se produjeron torturas ${ }^{51}$, salvo posibles casos muy aislados y públicamente denunciados por el propio ministro de Interior ${ }^{52}$.

Esto fue así debido al llamado público de que se respetara la vida de los vencidos, y de fuesen recibidos por la Cruz Roja $^{53}$ para su protección ${ }^{54}$. También la Iglesia recibió esta petición. Así lo recuerda una religiosa:

"Una mañana...eh, la radio, ya la radio de Nicaragua, que pasó a ser ya del Estado [...], empezaron a dar la noticia de que...que los guardias andaban (por ahí) y que por favor, tanto a los conventos, a las iglesias, a los colegios católicos y todo eso que...que les recibieran [...]. Yo había oído...estaba por radio continuamente que los que llegaran a asilarse y todo eso que podían llevarlos después a la Cruz Roja” ${ }^{55}$.

El titular de la cartera de Interior, Tomás Borge, fue el principal responsable de esta actitud humanitaria. Según una funcionaria de sus servicios de inteligencia, informante de la presente investigación, "era un hombre duro cuando tenía que ser duro", pero, "lo que yo te puedo decir es que en esa cárcel (que visitamos) estaba el hombre que había torturado al comandante, y lo perdonó" ${ }^{56}$. Pese a estas vivencias, su actitud siempre fue humanitaria, casi hasta el escrúpulo. Una informante, testigo de las visitas nocturnas de Borge a los presos así lo recuerda:

"Y en la noche se iba pabellón por pabellón y le preguntaba a la gente: “vos, ¿por qué estás preso?” [...], y yo lo tenía que anotar, y correr, y al día siguiente había que ir a ver quién era ese hombre, y a hacer justicia. Y el comandante no esperaba a que el tribunal especial de justicia [...] hicieran ese juicio: había que sacarlo, porque se estaba haciendo una injusticia con ese hombre" ${ }^{, 57}$.

50 La revolución sandinista abolió la pena capital, y al no ejecutar a nadie, se convirtió en la primera revolución de toda la Historia Contemporánea que mantuvo el poder sin derramamiento de sangre. (LÖWY, Michael: Guerra de dioses. Religión y política en América Latina, México, Siglo Veintiuno Editores S. A., 1999, p. 129).

51 Entrevista efectuada por el autor a Rafael Valdés Rodríguez, Managua, 1 y 2 de agosto de 2008.

52 CARDENAL, Ernesto: op. cit., 2004, p. 409.

53 La Cruz Roja Internacional, en boca de Carlos Bower, miembro de la Comisión que permaneció dos semanas en el país, elogió el comportamiento humanitario de los insurgentes por la rapidez con que se estaban liberando a los detenidos tras la insurrección final. Además, señaló que aun no teniendo la obligación de conceder el estatus de prisioneros a combatientes de un conflicto civil, los sandinistas lo habían extendido a los miembros de la exguardias nacionales, muchos de ellos criminales de guerra, torturadores y asesinos. ( $\mathrm{La}$ Prensa, 18 de agosto de 1979, Biblioteca José Coronel Urtecho, Universidad Centroamericana, Managua). 54 Entrevista realizada por el autor a Amparo Rubio, Ocotal, 11 de agosto de 2008.

55 Testimonio de una informante anónima. Fue inaudito que tras lo que se sufrió durante la dictadura, no se produjera un baño de sangre después de la victoria insurreccional. La causa puede deberse a la influencia de la Iglesia Católica. El propio Tomás Borge, ministro del Interior durante el sandinismo, lo reconoció explícitamente: "Me pareció que la participación de la Iglesia sería esencial para evitar que a la caída de la tiranía se desatara una matanza...Había un odio acumulado durante tantos años que yo temía estallara una violencia descontrolada contra los somocistas". (BROOK, Chris: "Ahora sí ya sabemos cual es la diferencia“, Revista Cultural Nicarauac, n 12, Managua, Ministerio de Cultura de Nicaragua, Abril, 1986, pp. 42-43).

56 Entrevista realizada por el autor a Amparo Rubio, Ocotal, 11 de agosto de 2008.

57 Ibídem. 
Así, buena parte de los soldados y militares somocistas salieron libres a los pocos meses $^{58}$. En este sentido, según el fiscal del Estado de EEUU Ramsey Clark, el sistema penal nicaragüense era de los mejores del mundo ${ }^{59}$. Sin embargo, un antiguo guardia nacional, informante en la presente investigación, que estuvo preso durante casi toda la década sandinista, da fe del hambre sufrido en la cárcel $^{60}$, y de las torturas presenciadas por él:

"Eran torturas [...], muchas y bien, bien pesadas [...]. Estaba... estaban investigando a un hombre [...], y por cuenta del preso, pues, se llenó de temor, de nervios $[\ldots]$ y a lo mejor le conocieron algo, un delito, le hallaron, y lo golpearon, fue golpeado. Le golpearon un golpe en la boca del estómago [...], como tres golpes [...], yo lo miré. Y muchos. Hubo otros que murieron" ${ }^{1}$.

Con respecto al tema de los derechos humanos, hubo denuncias acerca del carácter represor del sandinismo, señalándose 43 ejecuciones, 600 desaparecidos, dos fosas comunes y un centro de detención ilegal ${ }^{62}$. Sin embargo, no sólo no se ha podido demostrar la veracidad de estas acusaciones ${ }^{63}$, sino que el denunciante desmintió públicamente sus propias afirmaciones ${ }^{64}$.

\section{LA CONTRARREVOLUCIÓN}

Uno de los grandes problemas con que la revolución debió lidiar fue el del terrorismo de la contrarrevolución, también llamada contra. Ésta consistió en la oposición armada que fue organizada por sectores de la burguesía para abortar el proceso revolucionario. Directamente controlada por la CIA y subvencionada por el gobierno de EEUU, contó entre sus filas con antiguos guardias nacionales, campesinos descontentos e indios miskitos refractarios al nuevo Estado ${ }^{65}$. En 1982, la contra se estrenó dañando un puente sobre el río Coco, cerca de Ocotal, lo que se entendió como una declaración oficiosa de guerra ${ }^{66}$.

"Entonces me fui en un jeep con un jesuita de allá que andaba por aquí, y él me iba platicando de las tierras de Sandino, muy bueno, no sé cuánto...y yo no veía vehículos $[\ldots]$ y digo: "oye, esta bonita la plática, pero no veo vehículos".

58 Entre noviembre de 1979 y febrero de 1981 fueron detenidos 6.310 guardias nacionales. A ninguno de ellos se les aplicó la pena capital, 229 resultaron absueltos, 1760 fueron indultados o sobreseídos y 4321 resultaron condenados, como máximo a penas de treinta años (MOLERO, María: op. cit., 1988, p. 48).

59 Barricada, 12 de marzo de 1983, Biblioteca José Coronel Urtecho, Universidad Centroamericana, Managua.

60 Entrevista realizada por el autor a Francisco Cruz Maldonado en Ocotal el 14 de agosto de 2008.

61 Ibídem.

62 CHRISTIAN, Shirley: Nicaragua. Revolución en la familia, Barcelona, Editorial Planeta, 1986, pp. 141-42.

63 Ibídem, p. 125.

64 El director de la Comisión de Derechos Humanos, también dirigente del Partido Socialdemócrata, José Esteban González, tras hacer campaña por el extranjero denunciando torturas y desapariciones, regresó a Nicaragua. Después de una breve detención y puesta en libertad, desmintió sus acusaciones. Posteriormente se marchó de nuevo fuera de Nicaragua. (POZAS, Víctor S., La revolución sandinista (1979-1988), Madrid, Editorial S.A.L., 1988, p. 91).

65 MARTÍ I PUIG, Salvador: op. cit., 2004, pp. 197-204.

66 CHRISTIAN, Shirley: op. cit., 1986, p. 298. 
"No - dice- es que por esta zona están las bandas contrarrevolucionarias". Entonces entré en la cuenta de que ya estaba en otra situación"67.

Esta insurgencia armada tuvo como origen el hecho de que la burguesía, minoritaria y acostumbrada a controlar el país, hubiese perdido el $40 \%$ de su poderío económico, como ya hemos señalado, viéndose en el deber de acosar a un proceso que gozaba del apoyo de la mayoría de la población, para tratar de imponer su propio proyecto ${ }^{68}$. Para ello, el COSEP, agrupación de empresarios privados, lanzó el infundio de que Nicaragua se encaminaba hacia "un nuevo genocidio", al impulsar un régimen "marxistaleninista de espaldas al pueblo"69. El derechista diario La Prensa, por su parte, acusó al gobierno de abandonar el espíritu de los primeros días; finalmente, el presidente Ronald Reagan aprobó el envío de 19 millones de dólares para la contra, tras la expresa petición de la oligarquía nicaragüense al respecto, comenzando las actividades violentas ${ }^{70}$. Así fue el principio de una guerra cruenta:

"Comenzamos a luchar otra vuelta, nuevamente, con la contrarrevolución: luchamos, luchamos [...]: combates de hasta diecisiete días [...], sin comer [...], ahí no se duerme, este, se ponía unos cinco cuidando, y el resto combatiendo, tres durmiendo y así ratito, pegamos las pestañas"71.

Estos grupos armados, a diferencia de una guerrilla sandinista que nunca recurrió al terrorismo ${ }^{72}$, cometieron todo tipo de atrocidades entre masacres, secuestros, torturas y asesinatos $^{73}$. Trascribimos a continuación el testimonio de una informante, testigo de esas violaciones de los derechos humanos:

"Este muchacho, de aquí nomasito de Mozonte, se llama Concepción López [...]: este niño estaba convaleciente, lo secuestraron [...]: esos alambres eran eléctricos, se los tenían en la cara [...], entonces, pedazos de carne quedaban en los alambres; se lo pusieron en la espalda, le quitaron la camisa y se lo pusieron en la espalda [...]; tenía todo pura llaga la cara [...]: tenía 19 años" ${ }^{\text {"4 }}$.

Se trató de una guerra de desgaste donde, según el jesuita Zenteno, el 60\% del presupuesto del Estado se debía destinar para la guerra ${ }^{75}$ y que, por lo demás, dejó daños incalculables: 50.000 muertos y 12 mil millones de dólares en pérdidas y destruccio-

67 Entrevista realizada por el autor a Arnaldo Zenteno Vargas, S.J., en Managua el 22 de julio de 2008 68 VILAS, Carlos: op. cit., 1984, p. 202.

69 Ibídem, p. 210.

70 NÚÑEZ SOTO, Orlando: op. cit., 1987, pp. 122-27.

71 Entrevista realizada por el autor a Noel Eusebio González Vázquez en Ocotal el 14 de agosto de 2008

72 Entrevista realizada por el autor a Fernando Cardenal, S.J. en Managua, el 28 de julio de 2008.

73 Algunos ejemplos: en Jalapa, la contra secuestró a un campesino desarmado, lo torturaron, le sacaron los ojos y lo mataron; en la misma zona, en el lapso de 16 meses, mataron a veinticuatro personas entre campesinos, niños y técnicos; en Condega, en 1984, quemaron dos comunidades enteras, debiendo huir sus habitantes; en Palacagüina, ese mismo año, en una masacre fueron asesinadas más de veinticinco personas; en San Juan de Limay, en un solo mes de 1985, la contra llegó a asesinar hasta a veintitrés civiles. (SCHMIDT, Uli: "Los delegados de la palabra de Dios en la diócesis de Estelí. Aproximación a la trinchera teológica desde el campesinado en la nueva Nicaragua", VVAA: Nicaragua, trinchera teológica. Para una teología de la liberación desde Nicaragua, Managua, Centro Ecuménico Antonio Valdivieso, 1987, pp. 114-15).

74 Entrevista realizada por el autor a Doña Hulda Maritza Sandoval, en Ocotal el 9 de agosto de 2008

75 Entrevista realizada por el autor a Arnaldo Zenteno Vargas, S.J., en Managua el 22 de julio de 2008. 
nes $^{76}$, así como 250 mil desplazados ${ }^{77}$. Ante estas cifras, el ignaciano, informante de la presente investigación, se resiste a contemplar el conflicto como una guerra "de baja intensidad":

"Fíjese que los gringos tenían tres palabras pa la guerra: decían que era de larga duración: duró diez años. Cierto, ¿no? Decían de baja intensidad, pura hipocresía, porque de un país que entonces tenía tres millones y medio de habitantes, murieron más de 70.000 jóvenes, y unos 14.000 quedaron cojos o mancos, ciegos y paralíticos, ¿Cuál baja intensidad, no? Y la tercera, esa muy cierta, por desgracia, que era de desgaste: se desgastó vidas humanas en primer lugar, pero la economía del país...por ejemplo, del presupuesto nacional, el $60 \%$ se iba pa la guerra"78.

Con respecto a la responsabilidad estadounidense, según el activista Noam Chomsky, la contra estuvo controlada por el gobierno de Reagan, y directamente supervisada por la CIA ${ }^{79}$, quien daba las consignas de "asesinar, raptar, robar y torturar"

Finalmente, la insurgencia decidió forzar una paz al ver la imposibilidad de ganar la guerra, y al constatar que estaban perdiendo no sólo legitimidad internacional sino también apoyos internos ${ }^{81}$. Por fin, se llegó en 1988 a la firma de los acuerdos de Sapoá ${ }^{82}$, de cara al fin del conflicto armado. Eso sí, en el caso de que los norteamericanos, según el jesuita Mulligan, fuesen de fiar:

"Aunque hubo un cese de fuego [...] y se firmó un cese de fuego en el ochenta y...ocho, en Sapoá, ah, pero la contra seguía armada [...], y también con el presidente Bush no había ninguna certeza de que él hubiera reconocido una victoria electoral, un triunfo electoral" ${ }^{13}$.

\section{EL CONFLICTO DE LOS MISKITOS}

Uno de los asuntos más controvertidos de aquel tiempo fue el de las relaciones del gobierno sandinista con los miskitos, grupo étnico de la costa Atlántica que constituye el $5 \%$ de la población total de Nicaragua ${ }^{84}$, país del que se sienten ajenos por diferencias culturales y geográficas ${ }^{85}$.

76 CORTÉS, Benjamín: “Las iglesias evangélicas”, en G. Girardi y otros: Pueblo revolucionario, Pueblo de Dios, Managua, Centro Ecuménico Antonio Valdivieso, 1989, p. 130.

77 GARCÍA, Diamantino: op. cit., 1996, p. 586.

78 Entrevista realizada por el autor a Arnaldo Zenteno Vargas, S.J., en Managua el 22 de julio de 2008

79 CHOMSKY, Noam: La quinta libertad. La intervención de los Estados unidos en América Central y la lucha por la paz, Barcelona, Editorial Crítica, 1988, p. 209.

80 Eso declaró bajo juramento ante un tribunal internacional el portavoz de la contra Edgar Chamorro. (Ibídem, p. 28).

81 MARTÍ I PUIG, Salvador: La revolución enredada. Nicaragua (1977-1996), Madrid, Los Libros de la Catarata, 1997, pp.104-05).

82 Ibídem, p. 120.

83 Entrevista realizada por el autor a José Mulligan, S.J., en Managua el 8-09-09.

84 Dividido entre los siguientes grupos étnicos: 88 mil miskitos, 30 mil criollos, 8 mil sumos, 15 mil garífonas y 800 ramas, así como un millón doscientos mil mestizos provenientes de la zona del Pacífico. (NÜÑ̃Z SOTO, Orlando: op. cit., 1987, p. 167).

85 La población miskita era de raza e idioma distinto al resto de la población del país, se encontraba en la costa atlántica en situación de aislamiento geográfico, era de influencia anglosajona y de religión protestante, a diferencia del resto del país, cuya influencia era la hispánica y cuya religión mayoritaria era la católica. (CARDENAL, Ernesto; op. cit., 2004, p. 455). 
Estos indígenas, que no conocieron la represión somocista ${ }^{86}$, ni por tanto la lucha insurreccional más que de modo marginal ${ }^{87}$, debieron ver al sandinismo como algo ajeno a su realidad. Por todo esto, y por su carácter de nómadas, carentes del concepto de Estado-Nación y Frontera impuesto por el hombre blanco, cruzaban constantemente la frontera con Honduras ${ }^{88}$. Todo ello favoreció el que fueran terreno abonado para la infiltración de la CIA ${ }^{89}$ y las masacres de la contra ${ }^{90}$. Numerosos miskitos, de hecho, se integraron a estos grupos insurgentes ${ }^{91}$.

En este contexto se produjeron los actos de hostigamiento denominados como los de de la "Navidad Roja" que, apoyados por la CIA, y para provocar un levantamiento general, fueron atacadas instalaciones militares y centros civiles, muriendo unas 60 personas $^{92}$. Ante esto, el gobierno revolucionario se defendió pasando a la ofensiva: detuvo a 32 líderes miskitos, y al tratar de dar el alto a un alfabetizador indígena, se originó un disturbio que dejó 8 muertos (la mitad militares sandinistas) y otros 8 heridos $^{93}$. Fue, en el mejor de los casos, una falta de tacto ${ }^{94}$ : "Muchos se integraron a la contrarrevolución, allí, miskita, ¿verdad? Y, para ser honestos, les atacamos, tuvimos guerra con ellos: hubo guerra, enfrentamiento y crueldades de parte de ellos y de parte de nosotros" $" 95$.

Para acabar con la infiltración terrorista en territorio miskito, el gobierno de Managua decidió llevar a cabo algo discutible: destruir sus poblados y reubicar a sus moradores en otros construidos ad hoc ${ }^{96}$. Y aunque la operación se efectuó sin contar con la opinión de los indios, lo cierto es que los sandinistas procuraron, en la medida de lo posible, ganarse a esta población ${ }^{97}$. Para ello, entre otras medidas, equiparon sus nuevas casas con todas las comodidades:

"Pero los miskitos estaban sirviendo de base para la contrarrevolución, y entonces se decidió sacar a los miskitos de donde estaban y llevarlos a un lugar [...]: yo vi las casas, yo estuve allí [...]: se les construyó unas casas bonitas, bien hechitas [...], mejores de donde vivían pues. Se les instaló agua potable, se les

86 POZAS, Víctor S: op. cit., 1988, p. 193.

87 CORAGGIO, José Luis: op. cit., 1986, p. 62.

88 Entrevista realizada por el autor a José Dolores Cisne Contreras en Managua el 30 de julio de 2008.

89 POZAS, Víctor S., op. cit., 1988, pp. 203-04.

90 El doctor Ramón Moncada, médico que trabajó en la zona asistiendo la salud de sus habitantes, y equipando un hospital, afirma que a causa de la contra se han producido en población miskita hasta 64 casos de torturas y asesinatos. Y textualmente narra lo siguiente: "Y vimos: vestigios de comunidades que habían sido asoladas por la contrarrevolución (...), más de 80 comunidades misquitas, en donde la contra había asesinado a algún miembro de ellas, a ancianos llorando porque sus familias habían sido deshechas, pues la contra había secuestrado, violado, torturado y asesinado a algunos de ellos". (Barricada, 3 de marzo de 1982).

91 MARTÍ I PUIG, Salvador: op. cit., 1997, pp. 99-101.

92 En octubre y noviembre de 1981, grupos de miskitos entrenados en Honduras por exguardias somocistas y agentes de la CIA, asaltaron puestos de abastecimiento y centros de salud, atacaron a patrullas sandinistas y mataron a 60 personas. La intención fue crear la operación Navidad Roja, o intento generalizado de levantamiento antigubernamental. Para ello, aseguraron que el sandinismo pretendía bombardear sus comunidades, y que ellos en cambio les construirían viviendas y servicios de salud en Honduras. (POZAS, Víctor S: op. cit., 1988, pp. 203-04).

93 Ibídem, pp. 200-201.

94 Ernesto Cardenal afirma que el conflicto no se gestionó bien, al llevar a militares en lugar de antropólogos. CARDENAL, Ernesto; op. cit., 2004, p. 455).

95 Entrevista efectuada por el autor a Rafael Valdés Rodríguez, Managua, 1 y 2 de agosto de 2008.

96 Entrevista realizada por el autor a Rosa Julia Esquivel, Doña Pipe, en Managua, el 7 de septiembre de 2008

97 Ibídem. 
puso electricidad, se les levaron trastos de cocina, todo eso. Pero ellos no estaban acostumbrados a ese tipo de vida" ${ }^{98}$.

Este traslado fue explotado ante la opinión pública por la administración Reagan: la embajadora de EEUU en la ONU afirmó que 250 mil indígenas se encontraban "concentrados", ignorando que el total de ellos no llegaba a $150 \mathrm{mil}^{99}$. Sin embargo, el trato recibido por estos grupos étnicos de Nicaragua fue avalado tanto por la OEA, por la American Watch y por el Consejo Internacional de Tratados Indios (IITC) ${ }^{100}$. El activista Noam Chomsky fue aún más lejos al afirmar que estos miskitos de la Costa Atlántica tal vez fuesen los mejores tratados del continente, y que, de haber actuado así los indígenas estadounidenses que en nuestros días se movilizan por sus derechos, probablemente éstos hubieran sido asesinados ${ }^{101}$.

En todo caso, la fricción entre ambas partes llegó a su fin de una vez por todas: en 1985 se aceptó una autonomía que les permitía el acceso a sus tierras y a sus recursos, acabando con un conflicto que venía siendo usado por la contra y por la CIA ${ }^{102}$.

\section{REVOLUCIÓN: INSTITUCIONALIZACIÓN Y COLAPSO}

La década sandinista fue generosa en cuanto a libertades se refiere. Sin embargo, sí fue clausurado durante varias veces el diario La Prensa ${ }^{103}$, por recibir dinero de la CIA $^{104}$. Según Chomsky, si esto hubiera sucedido en EEUU (el que un medio de prensa reciba apoyo de una potencia agresora), sus propietarios inmediatamente hubieran sido detenidos ${ }^{105}$.

En 1984 se celebraron elecciones a la presidencia del país bajo el hostigamiento de la contra y las amenazas de invasión directa por parte de EEUU. En estos comicios, ganó con gran holgura Daniel Ortega, candidato del FSLN, al alcanzar el 65\% de las papeletas, según datos del conteo definitivo ${ }^{106}$ :

"El 84, que fue cuando se...ganó Daniel Ortega. Fueron muy, muy...ni tristeza nos dieron, porque ya todo el mundo sabía que esas elecciones se iba a ganar [...]: se sabía que las ganaba Daniel, la gente, todo el mundo estaba por...por legitimarla la...la llegada al poder del Frente Sandinista. La gente más bien estaba desesperada por ir a votar y darle el voto de confianza"107.

La constatada fiabilidad de la consulta, avalada por buena parte de la opinión pública norteamericana y de algunos periodistas y analistas del país norteño, según afirmó el rotati-

98 Entrevista efectuada por el autor a Rafael Valdés Rodríguez, Managua, 1 y 2 de agosto de 2008.

99 CARDENAL, Ernesto: op. cit., 2004, pp. 457-58.

100 POZAS, Víctor S.: op. cit., 1988, p. 206.

101 CHOMSKY, Noam: op. cit., 1988, p. 121.

102 NÚÑ̃Z SOTO, Orlando: op. cit., 1987, p. 168.

103 Entrevista realizada por el autor a Amparo Rubio, Ocotal, 11 de agosto de 2008.

104 POZAS, Víctor S: op. cit., 1988, p. 261.

105 CHOMSKY, Noam: op. cit., 1988, pp. 119-20.

$106 \mathrm{El}$ recuento de los comicios ofreció una abultada victoria del FSLN: de 1.170. 102 votos depositados, 729. 158 de estos fueron a favor de la agrupación sandinista, es decir, aproximadamente un $65 \%$ de los votantes. (CORAGGIO, José Luis: op. Cit., p. 74).

107 Entrevista realizada por el autor a Mercedes Ortega en Managua, el 9 de septiembre de 2008. 
vo progubernamental Barricada ${ }^{108}$, no fue impedimento para que de inmediato el presidente Ronald Reagan comenzara los preparativos de una invasión directa ${ }^{109}$. Ante esta amenaza, se activaron los mecanismos de defensa, lo cual pudo tener un efecto disuasorio:

"Hubo un intento serio, pero eh...no sé por qué pero gracias a Dios nunca lo lograron llevar a efecto. Puede ser que un elemento disuasivo era el hecho de que si venían, era tan grande la población nicaragüense que estaba adiestrada en el uso de armas y dispuesta a morir combatiendo" $"$.

La ofensiva militar no llegó, y la vida siguió su ritmo: dentro de la labor de institucionalización se abrió un proceso constituyente para elaborar la carta magna de 1987. Doña Pipe, informante de la presente investigación, fue diputada suplente durante dicha legislatura, y la recuerda del siguiente modo:

"Fue una experiencia buena, se estaba este... formulando la primera constitución política de la república: había mucho trabajo, salíamos a veces 3 de la mañana (y) a veces no cenábamos [...], o cenábamos con un café y un pastelito, nada más, pero allí no había...y el almuerzo, simplemente teníamos que anotar allí...era un almuerzo normal, pues no...no era derroche de nada" ${ }^{111}$.

Sin embargo, al final de la década sandinista aumentaron las estrecheces: la carestía vino a más, y los alimentos, combustibles y medicinas vinieron a menos, colapsando además las escuelas ${ }^{112}$. Así lo recuerda el padre Mulligan:

"Bueno: (arreciaron) las quejas sobre la falta de cosas en los mercados: que no había eso, que no había otro, filas largas, eh...dificultades en el sector de medicinas, bueno, y una inflación tremenda, tremenda [...]. Recuerdo que en el ochenta y ocho...ochenta y nueve tuvimos una inflación de treinta mil por ciento anual: en un año. Y, bueno, creo que sí: yo creo que la necesidad de dedicar más recursos a la defensa del país..."113.

108 Barricada, 5 de Noviembre de 1984.

109 Justo después de las elecciones de 1984 se temió la invasión abierta de EEUU: a 48 horas de la victoria sandinista se promulgó el Estado de Emergencia, y se activó todo el dispositivo de defensa civil, se 1levaron a cabo simulacros militares de defensa, ante un inminente ataque que fue denunciado ante el Consejo de Seguridad de la ONU. (MARTí I PUIG, Salvador: op. cit., 1997, p. 97).

110 Entrevista efectuada por el autor a Rafael Valdés Rodríguez, Managua, 1 y 2 de agosto de 2008.

111 Entrevista realizada por el autor a Rosa Julia Esquivel, Doña Pipe, en Managua, el 7 de septiembre de 2008. La Constitución de 1987 fue elaborada y promulgada desde la intención del Gobierno sandinista de institucionalizar el proceso de transformaciones sociales, en medio del conflicto armado de la contra. Las fuerzas no sandinistas que habían sido elegidas para la Asamblea también participaron en los debates de la elaboración. La carta magna, aun vigente, consagra el principio de soberanía popular, el sufragio universal y el pluralismo político, sin nombrar a ningún partido-guía. Consagra la división de poderes, prevé un Consejo Supremo Electoral y la Contraloría General de la República, encargada del control de las cuentas públicas. Otorga la autonomía a las comunidades de la Costa Atlántica. Garantiza los derechos individuales y la propiedad privada, dentro del marco de la economía mixta. Sin embargo, declaraba al ejército como Sandinista, y no aseguraba la independencia judicial, ya que los miembros de la Corte Suprema de Justicia serían nombrados por la Asamblea Nacional. (ÁLVAREZ ARGUELLO, Gabriel y VINTRÓ CASTELLS, Joan: "Evolución constitucional y cambios institucionales en Nicaragua (1987-2007”, en Salvador Martí i Puig y David Close (Eds.), Nicaragua y el FSLN. ¿Qué queda de la revolución?, Barcelona, Edicions Bellaterra, 2009, pp. 171-73).

112 MARTÍ I PUIG, Salvador: op. cit., 2004, p. 241.

113 Entrevista realizada por el autor a José Mulligan, S.J., en Managua el 8 de setiembre de 2008. 
A fines de los 80 la economía era un desastre: el PIB estaba destruido, y la inflación pasó del 70’3\% en 1979 al 1347’2\% en 1987. Para paliar esta realidad, el gobierno llevó a cabo un paquete de medidas con el que disminuyó la productividad y aumentó la pobreza ${ }^{114}$.

Ante este panorama, y por el deseo de que la guerra de la contra terminara definitivamente $^{115}$, la candidata de la derecha, Violeta Chamorro, ganó las elecciones de 1990 de un modo totalmente sorpresivo e inesperado, como afirma Arnaldo Zenteno, quien asegura textualmente que "el día de las elecciones todos decíamos que iba a ganar el Frente. Todos [...], porque era...todo el ambiente era del Frente, y ganaba la guerra" ${ }^{116}$. El sueño había acabado. Ahora empezarían las pesadillas:

“¡Horrible! Además: la tragedia de la derrota electoral, eso es una decisión popular. Obreros, campesinos, clase media es la que le dice "¡no!" a lo que creíamos que era la propuesta y el proyecto histórico esencial de Nicaragua: la nacionalidad, la liberación, la imaginación, el marco utópico" ${ }^{117}$.

114 No en vano, estas medidas fueron tachadas de "draconianas" por la CEPAL y de "cirugía sin anestesia" por el teólogo Xavier Gorostiaga. (MARTÍ I PUIG, Salvador: op. cit., 2004, p. 241).

115 Entrevista realizada por el autor a Amparo Rubio, Ocotal, 11 de agosto de 2008.

116 Según opinión de Fernando Cardenal, el hecho de que la revolución trabajase a favor de las masas obreras y campesinas les llevó a la convicción de la irreversibilidad del proceso, debido al voto de estas mayorías. Por lo tanto, se contaba con la victoria de 1990. (CARDENAL, Fernando: op. cit., 2008, p. 231). Sin embargo, el jesuita Zenteno, al escuchar a una niña afirmar que su padre votaría a Chamorro para que acabara la guerra, cayó en la cuenta, ya a posteriori, de que mucha gente no derechista habría optado por dicha opción de modo discreto, como algunos analistas y observadores habían advertido (Entrevista realizada por el autor a Arnaldo Zenteno Vargas, S.J., en Managua el 22 de julio de 2008).

117 Entrevista realizada por el autor a Julio Valle-Castillo en Managua el 13 de septiembre de 2008. 